1 Text Messages Promoting Mental Imagery Increase Self-Reported Physical Activity in Older

2 Adults: A Randomized Controlled Study

3 Nicolas Robin*, Lucette Toussaint**, Guillaume, R. Coudevylle*, Shelly Ruart*, Olivier

4 Hue* and Stephane Sinnapah*.

5

6 *Université des Antilles; Faculté des Sciences du Sport; Pointe-à-Pitre; France.

** Université de Poitiers; Université François Rabelais de Tours; Centre National de la

8 Recherche Scientifique; Centre de Recherches sur la Cognition et l'Apprentissage

9

10 Suggested running head: MENTAL IMAGERY, PHYSICAL ACTIVITY AND OLDER

11 ADULT

12

13 Correspondence concerning this article should be addressed to Nicolas Robin, Laboratoire

14 "Adaptation au Climat Tropical, Exercice \& Santé" (UPRES EA 3596), Campus Fouillole, BP

15 592, 97159, Pointe à Pitre Cedex, France. Mail: robin.nicolas@hotmail.fr;

16 Fax number: (00 33) 0590 48.31.70; telephone number: (00 33) 059048.31 .69

17

18

19

20

21

22

23

24

25

26 
Abstract

2 This study tested whether text messages prompting older adults to perform mental imagery

3 would increase Aerobic Physical Activity (APA) duration using a randomized parallel trial

4 design.

5 Method: Older adults were assigned to an Imagery 1, Imagery 2 or Placebo group. For 4

6 weeks, each group was exposed to two conditions (morning text message vs. no morning text

7 message). In the morning message condition, the Imagery groups received a text message

8 with the instruction to mentally imagine performing an APA and the Placebo group received a

9 placebo message. All participants received an evening text message: "Did you do your cardio

10 today? If yes, what did you do?" 3 days per week.

11 Results: Participants of the Imagery groups reported significantly more weekly minutes of

12 APA in the morning text message condition compared with the no morning message

13 condition.

14 Conclusion: Electronic messages was effective at increasing minutes of APA in older adults.

15 Keywords: cell phone, mental imagery, older adult, physical activity

16 
1 Text Messages Promoting Mental Imagery Increase Self-Reported Physical Exercise in Older Adults: A Randomized Controlled Study

3

\section{Increasing Physical Activity for Health in Older Adults}

Physical inactivity has been estimated to cause 3.2 million deaths per year (WHO, $2013^{\mathrm{i}}$ ) and was the fourth leading risk factor for global mortality in 2011, accounting for more than $20 \%$ of the diabetes, cancer and ischemic heart disease cases (World Health Organization: WHO, $2011^{\mathrm{ii}}$ ). Conversely, physical activity has a well-documented positive impact on aging (Albinet, Boucard, Bouquet, \& Audiffren, 2010; Charansonney, 2011; McPhee et al., 2016; Stacey, Kozma, \& Stones, 1985) and by consensus is today considered a medicine (Taylor, 2014). The WHO currently recommends a minimum of 150 minutes of physical activity per week. Nevertheless, despite the wide disparity across studies (Sun, Norman, \& While, 2013), it seems that only $17 \%$ of the adults between 55 and 64 years old and less than $16 \%$ of those who are older are meeting this recommendation (Centers for Disease Control \& Prevention, 2013; Myers \& Gonda, 1986). The worldwide community of researchers on chronic diseases is consequently struggling to find the best strategies to encourage people to be more active (Denison, Vist, Underland, \& Berg, 2014). The strategies of health promotion and physical activity campaigns are a major center of interest (Brawley \& Latimer, 2007; Leavy, Bull, Rosenberg, \& Bauman, 2011) as it is assumed that these campaigns can have a significant impact on behavior. From this perspective, several innovative strategies have been explored, such as using the internet (Duncan et al., 2014), personalized videos (Vandelanotte et al., 2015), video games (Studenski et al., 2010) and mobile devices (Fong et al., 2016; Johnston, Hoffman, \& Thornton, 2014). The latter in fact led to the concept of mobile health (mHealth) (Fiordelli, Diviani, \& Schulz, 2013; O'Reilly \& Spruijt-Metz, 2013).

\section{Text Messaging as a Way to Increase Physical Activity in Older Adults}


Although the use of new technologies generally spreads quickly, fewer than $20 \%$ of

2 UK adults older than 65 years and at risk of type 2 diabetes owned a smartphone in $2013^{\text {iii }}$,

3 but $77 \%$ in the $64-74$ age group owned a non-smart mobile phone in $2011^{\mathrm{iv}}$. Texting as a tool

4 for health promotion has therefore become a focus in mHealth research (Hall, Cole-Lewis, \&

5 Bernhardt, 2015; Morton et al., 2015) based on the idea that, like marketing strategies, it may

6 be able to prompt people to change their behaviors in a desired way (Cole-Lewis \& Kershaw,

7 2010). The effectiveness of texting in promoting physical activity has in fact been

8 documented (for a review, see Fanning, Mullen, \& McAuley, 2012) and this strategy was

9 found to generate positive feedback and attitudes (Gerber, Stolley, Thompson, Sharp, \&

10 Fitzgibbon, 2009). Given the observations that older adults are increasingly using cell phones

11 (Selwyn, Gorard, Furlong, \& Madden, 2003 ${ }^{\mathrm{V}}$ ) and that they have easier access to these phones

12 than to other technologies (Gerber, Olazabal, Brown, \& Pablos-Mendez, 2010), designing new ways to use them to promote health (Gell, Rosenberg, Demiris, LaCroix, \& Patel, 2015) and physical activity (Morton et al., 2015; O'Reilly \& Spruijt-Metz, 2013) has become an obvious research objective. Several studies (Antoine Parker \& Ellis, 2016; Kim \& Glanz, 2013; Muller, Khoo, \& Morris, 2016) have shown that text messaging increases certain domains of self-reported Aerobic Physical Activity (APA) and one study reported an objective increase in pedometer measurements (Kim \& Glanz, 2013).

Mental Imagery as an Innovative Way to Increase Physical Activity in Older Adults

Mental Imagery (MI) refers to the mental simulation or re-creation of a perceptual experience (Kosslyn, Ganis, \& Thompson, 2001). MI can be carried out in various ways, including auditory, olfactory, tactile, gustatory, kinesthetic, and visual modes (Cumming \& Williams, 2014). In the physical activity sciences, MI has been widely explored as a strategy to enhance sports performance (Di Rienzo et al., 2015; Robin et al., 2007) or as a tool in 
1 visual and motor aspects. However, occasional practitioners and non-athletes generally report

2 that visual imagery is the easiest to use (Lorant \& Nicolas, 2004). A comprehensive yet

3 inexpensive method of determining a person's abilities for visual and kinesthetic imagery is

4 the self-report questionnaire (Hall, 2001). According to Williams et al. (2012), one of the

5 most popular and commonly used questionnaires is the revised Movement Imagery

6 Questionnaire (MIQ-R; Hall \& Martin, 1997), which has proven valuable for controlling for

7 individual differences in imagery interventions (Debarnot, Sahraoui, Champely, Collet, \&

8 Guillot, 2012; Robin et al., 2007).

Many years ago, Paivio (1985) proposed that MI in sports, or "sport imagery," has two main roles that can be broken down into five non-exclusive functions. Mentally rehearsing race plans and strategies of play (CG; cognitive general imagery) or skills (CS; cognitive specific imagery) are proposed to be the two cognitive functions of sport imagery. Imagining the arousal and anxiety associated with performing (MG-A; motivational general-arousal imagery), imagining being in control and feeling confident (MG-M; motivational general-mastery imagery) and imagining goal achievement and accomplishment (MS; motivational specific imagery) are proposed to be the three motivational functions. The Sport Imagery Questionnaire (SIQ) (Hall, Mack, Paivio, \& Hausenblas, 1998) was designed to explore these five domains, respectively: SIQ CG, CS, M-GA, M-GM and MS. have been documented, especially in the field of eating disorders (Missbach, Florack, \& 21 Konig, 2015). In the field of physical activity promotion, very few works are available (Chan \& Cameron, 2012; Martin \& Hall, 1995). MI was found to increase the intrinsic motivation and quantity of practice of beginner golfers (Martin \& Hall, 1995). It was also found to increase approach motivation, intentions post-session and action planning for physical activity in non-active adults (Chan \& Cameron, 2012). 
In the sports domain, mental coaches usually include MI for training and competition programs (Rushall, 1991). As these coaches cannot always be physically present to guide the imagery sessions (e.g., international competitions), they frequently use cell phones and particularly text messages to give the imagery instructions (Target, 2012). We might therefore expect that this kind of procedure would also be beneficial for non-athletes and older adults.

Indeed, in the marketing context, MI via text messages is used to prompt purchases and purchase intent in consumers of all ages (Lao, 2011). Based on the assumption that MI can increase the duration of physical practice (Hall et al., 1998), we hypothesized that an MI prompt via cell phone would increase APA duration by strengthening motivation.

The aim of this study was to determine whether MI text messages would increase the minutes of APA in older adults. As observed by Martin and Hall (1995) with beginners, we assumed that the effectiveness of the motivation specific (MS) function of imagery, which is a means of modifying cognitions related to goals and motivation, would increase the minutes of APA in the imagery groups. APA prompts sent 3 days per week therefore supplemented a twice-weekly strength training program with a fitness instructor. However, the participants were not currently meeting the WHO recommendation of 150 minutes per week of APA. The aim of this research was to test the efficacy of the imagery intervention for increasing weekly minutes of APA, not necessarily to achieve 150 minutes or more.

\section{Methods}

\section{Trial design}

The study was a randomized controlled trial with a parallel design of three arms (Figure 1).

\section{Participants}

Eighty-nine volunteers ( 49 females, 40 males; $M_{\text {age }}=62.56$ years, age range: $51-73$ years) were recruited from a certified fitness center for older adults in La Rochelle, France. 
1 They all met the following inclusion criteria: (1) 50 years of age or older, (2) member of the

2 fitness center for at least 6 consecutive months, (3) currently participating in group strength

3 training with a professional fitness instructor at least twice a week but not meeting the WHO

4 recommendation for weekly APA, and (4) able to send and receive e-mail and/or text

5 messages from a cell phone over a 4-week period. Two participants ( 1 female and 1 male)

6 were excluded because they reported having low imagery ability, and 87 volunteers (47

7 females, 40 males; $M_{\text {age }}=62.87$ years, age range: $51-73$ years) thus were retained for the

8 entire experimental procedure (see Table 1 for demographic and clinical characteristics for

9 each group). The experiment was approved by the local ethics committee and was conducted

10 in accordance with the Declaration of Helsinki.

11

Table 1 near here

\section{Procedure and Intervention}

All participants were successively and in random order exposed to two 2-week periods (session 1: weeks 1-2 / session 2: weeks 3-4) from 3 September to 1 October 2016. At the beginning of the study, all the participants met together, and the Principal Investigator (PI, the first author) presented the procedure, explained how to carry out the visual and kinesthetic imagery, and answered questions. The participants then signed an informed consent form, filled out a personal information questionnaire, and completed two questionnaires assessing imagery ability and use. They were then randomly assigned to the Imagery 1, Imagery 2 (with a similar but counterbalanced condition to control for the order effect) or Placebo group by drawing lots made by the PI, as illustrated on Figure 1. 
1

The study lasted 4 weeks. The Imagery and Placebo groups received a morning text message (at 7:00 am) 3 days per week for 2 weeks. In the other 2 weeks, they received no morning messages. The morning message for the Imagery groups told them to "Visually imagine yourself performing a cardio activity," whereas for the Placebo group, the message was the exchange rate for the euro from the day before: for example, " 1 euro $=1.07$ dollars." After receiving the morning text message, the Imagery and Placebo groups simply had to send the message "received" to the PI.

All the participants also received an evening text message at 7:30 pm, 3 days a week for 4 weeks, asking "Did you do your cardio today?" Once the evening text messages were received, they completed the APA participation form by cell phone e-mail or text message and sent it to the PI. They had to respect a specified answer format, and when the response was "yes," they were expected to report the type of APA, duration in minutes, and intensity (moderate or vigorous).

\section{Measures}

Electronic Aerobic Physical Activity Participation Form. The electronic APA participation form, previously used by Antoine Parker and Ellis (2016), asked two questions: “Did you do your cardio today? and "If yes, what did you do?". As noted, when APA was reported, the participants specified the type of activity (e.g., bike, walk, swim, etc.), duration in minutes and intensity (moderate or vigorous). As bias can occur with self-report questionnaires, we used the French version of the Marlowe-Crowne Social Desirability Scale-short form C (MCSD) (Blais, Lachance, \& Riddle, 1991; Verardi et al., 2010) and, as recommended by Crowne and Marlowe (1960), divided the participants into three groups: low scorers $(0-3, n=13)$, average scorers $(4-7, n=57)$ and high scorers $(8-13, n=17)$. 
Imagery Ability. We assessed individual imagery ability to ensure that the sample did not include anyone with extremely high or low mental imagery ability (see Robin et al., 2007;

3 for a similar procedure) and especially ensured that none of the participants encountered difficulties in realizing visual imagery. Before the beginning of the experiment, all the participants completed the Movement Imagery Questionnaire-Revised (MIQ-R) (Hall \&

6 Martin, 1997). The MIQ-R measures movement imagery ability for basic and daily life movements. The MIQ-R is an 8-item self-report questionnaire in which participants rate the ease or difficulty of forming a mental representation using two 7-point Likert-type scales $(1=$ very hard to see/feel and $7=$ very easy to see/feel) referring to visual and kinesthetic imagery, respectively. Psychometric properties of the MIQ-R have been consistently adequate, with a Cronbach (1951) $\alpha$ of .82 for both visual and kinesthetic scales (Lorant \& Nicolas, 2004). is rated on 7-point Likert-type scale $(1=$ rarely use that function of imagery and $7=$ often use that function of imagery). An average frequency score for the participants' use of each of the five functions was then calculated. Internal consistency values range from $\alpha=.70$ to $\alpha=.88$, are satisfactory for the five SIQ subscales, and the scale possesses good validity (Hall et al., 1998). The sample was divided into three groups based on the SIQ MS scores (high, medium and low MS groups) to specifically evaluate the influence of the motivational specific

21 function of imagery.

\section{Preliminary Data Analysis}

We first examined the MIQ-R scores and each of the five SIQ scores across the 
1 checked for MIQ-R and each of the SIQ scores outliers considering values more than 2 SD

2 above or under the mean.

Second, to evaluate the eventual influence of social desirability, two one-way ANOVAs were performed. The first compared the low, average and high scorer groups with regard to the increase in minutes of APA. The second compared the MCDS scores between each group (Imagery 1 vs. Imagery 2 vs. Placebo).

\section{Preliminary Results}

Imagery Use and Ability. The MIQ-R visual and SIQ scores (mean, standard deviation and range) are presented in Table 2. Two of the participants had MIQ-R visual scores lower than 16 (corresponding to "hard to see/feel" for all the items of the questionnaire) and their data were excluded from the statistical analyses. The ANOVAs revealed no main group effect on the MIQ-R visual scores, $F(2,84)=0.11, p>.05$, or the five functions of the SIQ scores (CS, CG, MS, M-GM, M-GA), $F(2,84)=0.03, p>.05, F(2$, $84)=0.85, F(2,84)=0.58, F(2,84)=0.02, F(2,84)=1.01$, respectively $(p s>.05)$. minutes of APA, $F(2,84)=0.62, p=0.53$ (Table 3 ), and comparable social desirability in the experimental groups, $F(2,84)=0.05, p=0.95$ (Table 4). 
To determine whether the two Imagery groups could be combined, the order effect (Imagery 1: "Imagery morning message condition followed by no morning message condition" versus Imagery 2: "no morning message condition followed by Imagery morning message condition") on APA was then explored by a two-way ANOVA with a group factor and a session factor, APA being the dependent variable.

We then performed a two-way ANOVA to explore the effect of condition and session on the minutes of APA on the whole sample. To evaluate the influence of the MS function of imagery on the increase in minutes of APA (mean differences between morning message and no morning message conditions on minutes of APA) for the Imagery group participants, a one-way ANOVA compared the low, medium and high MS groups.

For all analyses, the significant main effects and interactions were broken down using the HSD Tukey test for the one-way ANOVA and the Newman-Keuls test for the ANOVA with session. Normality was checked (Kolmogorov-Smirnov test), effect sizes $\left(\eta_{\mathrm{p}}{ }^{2}\right)$ were indicated, and $\alpha$ was set at .05 for all the analyses.

\section{Results}

\section{Aerobic Physical Activity}

The weekly minutes of APA according to experimental condition are presented as means and standard deviations (see Table 5). The first two-way ANOVA revealed that there was no order effect on minutes of APA in either of the two Imagery groups, $F(1,56)=0.01, p$ $<.01$. We therefore combined the two groups into one.

We then performed another ANOVA to explore the effect of group (Imagery vs. Placebo) on minutes of APA with the type of morning message (imagery message vs. placebo message) as a between-subject factor and a repetition factor (morning message vs. no morning message) as a within-subject factor. 
The ANOVA revealed a significant main effect of group, $F(1,85)=9.61, p=.002, \eta_{\mathrm{p}}{ }^{2}$

$2=0.10$, and a significant main effect of type of morning message, $F(1,85)=28.85, p=.000$,

$3 \eta_{\mathrm{p}}{ }^{2}=0.25$. Moreover, the ANOVA revealed a significant interaction between group and type

4 of morning message, $F(1,85)=26.01, p=.000, \eta_{\mathrm{p}}{ }^{2}=0.24$. The post-hoc Newman-Keuls test

5 revealed that the participants of the Imagery group reported significantly more average

6 weekly minutes of APA $(M=99.53)$ in the morning imagery message condition compared

7 with the no morning message condition $(M=72.73)$. Moreover, as illustrated in Figure 2, the

8 participants of the Placebo group showed no significant difference between the morning

9 placebo message condition $(M=72.10)$ and the no morning message condition $(M=71.41)$.

10 None of the participants reported vigorous APA in their electronic responses.

Table 5 and Figure 2 near here

\section{Influences of SIQ MS Scores on APA}

Since "4" was the most frequently reported SIQ MS score and represented more than half the sample, we divided the sample into three groups: the low MS group with scores lower than $4(n=15)$, the medium MS group with scores equal to $4(n=32)$, and the high MS group with scores higher than $4(n=11)$. The ANOVA revealed a main effect of group, $F(2,55)=$ $3.65, \eta_{\mathrm{p}}{ }^{2}=0.06$, on the increase in minutes of APA. The post-hoc HSD Tukey test revealed that participants in the high and medium SIQ MS groups had greater increases in minutes of APA than participants in the low SIQ MS group (Figure 3). 


\section{Discussion}

\section{$2 \quad$ Limitations}

The duration of the morning text message condition ( 2 weeks) could be considered short, despite its positive results. However, the study objective was to determine whether text messages to prompt mental imagery would increase minutes of APA in older adults, and we compared our findings with those of other studies using similar protocols to facilitate the interpretation of the results (i.e., Antoine Parker et al., 2016; Prestwich, Perugini, \& Hurling, 2010). Our study should thus be viewed in the context of previous research with similar characteristics that also demonstrated the effectiveness of prompts for changing behavior (Antoine Parker et al. 2016; Fry \& Neff, 2009). The results are promising, suggesting the positive effects of cell phone imagery prompts to promote short-term APA. Further research is needed to evaluate whether this strategy is effective for long-term APA participation. The self-reporting of APA minutes might be another limitation, although this was modulated by the absence of any group difference according to social desirability. We may assume that a few participants over- or underestimated their minutes of APA, and this may have been the case with the evaluation of the intensity of APA, as well (none of the participants reported vigorous activity). Further research is needed using objective measurements of APA, such as heart rate monitoring, pedometers or doubly-labeled water.

\section{Generalizability}

The aim of this study was to determine whether cell phone prompts with imagery scripts would increase APA participation in adults aged 50 years and older. The results showed that, in the Imagery groups, the average weekly minutes of APA were significantly higher in the morning text message condition, during which participants had to visually imagine themselves doing an APA, than in the no morning message condition. The results of this original study are consistent with previous research showing that cell phone prompts 
1 related to physical activity increased the physical activity of younger adults (Fanning et al.,

2 2012; Fry \& Neff, 2009) and older adults (Antoine Parker \& Ellis, 2016; Kim \& Glanz, 2013).

3 Indeed, the latter authors showed a significantly greater weekly duration of APA in a group

4 that received the electronic reminder in the morning than during the control condition when

5 the morning reminder was not delivered. Moreover, our use of a Placebo group showed that a

6 placebo morning message, which had no relation to physical activity but merely indicated the

7 euro versus dollar exchange rate, had no influence on APA. This non-significant result is

8 important because it suggests that the Imagery group participants benefited from the message

9 content and not from the message itself. An MI message is therefore useful to improve APA

10 duration in older adults and may also be beneficial for younger participants or pregnant

11 women, for example. MI prompts can complete or replace other prompts that suggest or insist

12 on APA. The act of imagining oneself engaged in physical activity could be considered a self-

13 motivational technique and probably activates a specific neural network that incites this

14 behavior.

\section{Interpretation}

The results of the current study extend the literature by providing evidence that imagery text delivered via cell phones can also be a successful strategy for increasing weekly minutes of APA among older adults. Indeed, the increase of APA was about $36.8 \%$ (with a quite small sample size $\eta_{\mathrm{p}}{ }^{2}=0.24$ ) with morning imagery text. It seems that imagery text 20 prompts are as effective as other prompts like "Don't forget to do cardio today" used in 21 Antoine Parker et al. (2016) study, for example, in which the increase was $35.2 \%$ (with a small sample size $\eta_{\mathrm{p}}{ }^{2}=0.18$ ). Moreover, it seems important to note that in the morning text condition, participants of the Imagery groups averaged about 33 minutes of APA each message day versus 24 minutes of APA on the days without the morning text message or 23 minutes of APA for the Placebo group participants who received a placebo morning message. 
1 We can assume that if the MI messages had been delivered 4 to 5 days per week, the

2 participants would have been on track to meet the WHO physical activity recommendation

3 (150 weekly minutes of APA).

As hypothesized, the results suggest that imagery text messages are an effective intervention strategy for increasing APA in adults 50 years and older who regularly engage in

6 physical activities. As Paivio (1985) observed, MI is frequently used to enhance sports

7 performance. It has nevertheless been reported that the beneficial effects of MI on sports performance are modulated by numerous factors (Hall, 2001). For example, Short, Tenute, and Feltz (2005) suggested that individual differences in imagery ability influence the frequency of imagery use and how effective the imagery will be. Furthermore, the differences in imagery ability may be one reason why people choose not to use imagery even when it could be beneficial. In order to control for the influence of this factor, all the participants completed the MIQ-R and none of them were categorized as poor or good imagers (Robin et al., 2007). Another factor that can influence the beneficial effects of MI is the fitness level of the participants. Most of the sports imagery research has been conducted with adult athletes (Hall et al., 2009). According to Martin and Hall (1995), these athletes use imagery to modify cognitions and regulate arousal and anxiety, which are classed as serving motivational general-arousal and motivational general-mastery functions. When these athletes need to learn or improve movement performance, they use the cognitive specific function of imagery, and for strategies, game planes and routines, they use the cognitive general function. Moreover, Hall and collaborators (1998) suggested that athletes use all five functions of imagery to a greater extent than amateur or recreational athletes. Nordin and Cumming (2007), on the other hand, revealed that athletes show the lowest frequency scores for MS imagery, and athletes and non-athletes differ in their imagery use. Indeed, in the early stages of skill acquisition, novices attend to cognitive cues regarding the skill being learned and use imagery primarily 
1 for its cognitive function to assist in organizing information (about the skill or strategy) at the

2 central processing level (Murphy \& Jowdy, 1992). However, it should be noted that the older

3 adults in this study were not learning a new task or movement, which probably explains their

4 higher scores on the MS imagery function than the other four functions. Indeed, the other

5 functions are more oriented toward competition or learning, whereas MS imagery entails

6 imagining goal achievement and accomplishment. Moreover, our results are consistent with

7 those of Martin and Hall (1995) with beginner golfers, as these authors demonstrated that MS

8 imagery is effective for modifying cognitions related to goals and motivation. In their study,

9 the participants with six imagery sessions spent more time practicing a golf-putting task and

10 adhered more closely to their training program than the participants in the no-imagery control

11 group. A complementary analysis revealed that the participants who reported medium and

high SIQ MS scores had greater increases in APA duration than those with low SIQ MS

scores. These results confirm the literature and are consistent with the idea that MS imagery enhances motivation (Martin et al., 1999) to practice a physical activity. participation in older adults (Antoine Parker et al., 2016; Tabak, Op den Akker, \& Hermens, 2014) and none has tested mental imagery text messages. The results of our study confirm previous research results indicating that electronic prompts can increase APA in older adults and show the benefits of mental imagery messages. As suggested by Paivio (1985), mental

20 imagery has a motivational role that can improve physical practice. The use of mental

21 imagery text messages may be an easy-to-use, cost-effective and beneficial method to increase APA in older adults. 
$1 \quad{ }^{i}$ World Health Organization Diet and Physical Activity Factsheet. Secondary Diet and

2 Physical Activity Factsheet 2013.

3 http://www.who.int/dietphysicalactivity/factsheet_inactivity/en/index.html

$4 \quad$ ii World Health Organization. Global status report on noncommunicable diseases 2010.

5 Geneva: WHO Press; 2011.

$6 \quad$ iii Tech Tracker Quarterly Release: Q4 2013. Ipsos Media; 2013. [2015-08-03]. webcite

7 https://www.ipsosmori.com/DownloadPublication/1630_IpsosMediaCT_Techtracker_Q4_20

$8 \quad 13 . p d f$.

9 iv A nation addicted to smartphones. London, UK: Ofcom; 2011. [2015-08-03]. webcite

10 http://media.ofcom.org.uk/news/2011/a-nation-addicted-to-smartphones/

11 ' Selwyn N., Gorard S., Furlong J., Madden L. (2003). Older adults' use of information and

12 communications technology in everyday life. Ageing and Society, 23, 561-582 


\section{References}

Albinet, C., Boucard, G., Bouquet, C., \& Audiffren, M. (2010). Increased heart rate variability and executive performance after aerobic training in the elderly. European Journal of Applied Physiology, 109, 617-624. doi:10.1007/s00421-010-1393-y

Antoine Parker, C., \& Ellis, R. (2016). Effect of electronic messaging on physical activity participation among older adults. Journal of Aging Research, 2016, 1-6. doi.org/10.1155/2016/6171028

Blais, M.R., Lachance, L., \& Riddle, A. (1991). Validation de la version française de la mesure de désirabilité sociale de Marlowe-Crowne [Validation of the French version of the Marlowe-Crowne measure of social desirability]. Unpublished manuscript, University of Quebec, Montreal, Canada.

Brawley, L. R., \& Latimer, A. E. (2007). [Physical activity guidelines for Canadians: strategies for dissemination of the message, expectations for change and evaluation]. Applied Physiology Nutrition and Metabolism, 32, 189-205. doi:10.1139/H07-159

Centers for Disease Control and Prevention, "Adult participation in aerobic and muscle strengthening physical activities: United States, 2011," Morbidity and Mortality Weekly Report (MMWR), 62(17), pp. 326-330, 2013.

Chan, C. K., \& Cameron, L. D. (2012). Promoting physical activity with goal-oriented mental imagery: A randomized controlled trial. Journal of Behavioral Medicine, 35(3), 347363. doi:10.1007/s10865-011-9360-6

Charansonney, O. L. (2011). Physical activity and aging: A life-long story. Discovery Medicine, 12(64), 177-185.

Cole-Lewis, H., \& Kershaw, T. (2010). Text messaging as a tool for behavior change in disease prevention and management. Epidemiologic Reviews, 32, 56-69. doi:10.1093/epirev/mxq004 
1 Crowne, D., \& Marlowe, D. (1960), A new scale of social desirability independent of psychopathology, Journal of Consulting Psychology, 24, 349-354.

3 Cumming, J., \& Ramsey, R. (2009). Sport imagery interventions. In S. Mellalieu, \& S. Hanton, S (Eds.) Advances in Applied Sport Psychology: A Review (pp. 5-36). Routledge, London.

Debarnot, U., Sahraoui, D., Champely, S., Collet, C., \& Guillot, A. (2012). Selective influence of circadian modulation and task characteristics on motor imagery time. Research Quarterly for Exercise and Sport, 83, 442-50.

Denison, E., Vist, G. E., Underland, V., \& Berg, R. C. (2014). Interventions aimed at increasing the level of physical activity by including organised follow-up: A systematic review of effect. BMC Family Practice, 15, 120. doi:10.1186/1471-2296$15-120$

Dishman, R. K., \& Buckworth, J. (1996). Increasing physical activity: a quantitative synthesis. Medicine \& Science in Sports \& Exercise, 28, 706-719.

Di Rienzo, F., Blache, Y., Kanthack, T. F., Monteil, K., Collet, C., \& Guillot, A. (2015). Short-term effects of integrated motor imagery practice on muscle activation and force performance. Neuroscience, 305, 146-156. doi:10.1016/j.neuroscience.2015.07.080

Duncan, M., Vandelanotte, C., Kolt, G. S., Rosenkranz, R. R., Caperchione, C. M., George, E. S., . . Mummery, W. K. (2014). Effectiveness of a web- and mobile phone-based intervention to promote physical activity and healthy eating in middle-aged males: randomized controlled trial of the ManUp study. Journal of Medical Internet Research, 16(6), e136. doi:10.2196/jmir.3107

Fanning, J., Mullen, S. P., \& Mcauley, E. (2012). Increasing physical activity with mobile devices: A meta-analysis. Journal of Medical Internet Research, 14, 161-177. 
1 Fiordelli, M., Diviani, N., \& Schulz, P. J. (2013). Mapping mHealth research: a decade of evolution. Journal of Medical Internet Research, 15(5), e95. doi:10.2196/jmir.2430

3 Fong, S. S., Ng, S. S., Cheng, Y. T., Zhang, J., Chung, L. M., Chow, G. C., . . Macfarlane, D. J. (2016). Comparison between smartphone pedometer applications and traditional pedometers for improving physical activity and body mass index in communitydwelling older adults. Journal of Physical Therapy Science, 28(5), 1651-1656. doi:10.1589/jpts.28.1651

Fry, J. P., \& Neff, R. A. (2009). Periodic prompts and reminders in health promotion and health behavior interventions: Systematic review. Journal of Medical Internet Research, 11, 16-52.

Gavilán, B. D., Avello, I. M., \& Abril, B. C. (2014). The mediating role of mental imagery in mobile advertising. International Journal of Information Management, 34, 457-464.

Gerber, B. S., Stolley, M. R., Thompson, A. L., Sharp, L. K., \& Fitzgibbon, M. L. (2009). Mobile phone text messaging to promote healthy behaviors and weight loss maintenance: a feasibility study. Health Informatics Journal, 15, 17-25.

Gell, N. M., Rosenberg, D. E., Demiris, G., LaCroix, A. Z., \& Patel, K. V. (2015). Patterns of technology use among older adults with and without disabilities. Gerontologist, 55(3), 412-421. doi:10.1093/geront/gnt166

Gerber, T., Olazabal, V., Brown, K., \& Pablos-Mendez, A. (2010). An agenda for action on global e-health. Health Affair (Millwood), 29(2), 233-236. doi:10.1377/hlthaff.2009.0934

Hall, C. R. (2001). Measurement Imagery Abilities and Imagery Use. Advances in sport and exercise psychology measurement. Purdue University Editor, 9, 165-172. 
1 Hall, C. R., \& Martin, K. (1997). Measuring movement imagery abilities: A revision of the movement imagery questionnaire. Journal of Mental Imagery, 21, 143-54. doi:10.1037/t07979-000

4

Hall, C. R., Mack, D., Paivio, A., \& Hausenblas, H. (1998). Imagery use by athletes: Development of the sport imagery questionnaire. International Journal of Sport Psychology, 29, 73-89.

Hall, A. K., Cole-Lewis, H., \& Bernhardt, J. M. (2015). Mobile text messaging for health: A systematic review of reviews. Annu Rev Public Health, 36, 393-415. doi:10.1146/annurev-publhealth-031914-122855

Johnston, W., Hoffman, S., \& Thornton, L. (2014). Mobile health: A synopsis and comment on "Increasing physical activity with mobile devices: a meta-analysis". Translational Behavioral Medicine, 4(1), 4-6. doi:10.1007/s13142-014-0254-3

Kim, B. H., \& Glanz, K. (2013). Text messaging to motivate walking in older African Aamericans: A randomized controlled trial. American Journal of Preventive Medicine, 44, 71-75.

Kosslyn, S. M., Ganis, G., \& Thompson, W. L. (2001). Neural foundations of imagery. Nature Reviews Neuroscience, 2(9), 635-642. doi:10.1038/35090055

Lao, A. (2011). Etude exploratoire des effets de l'imagerie mentale issue de la présentation des produits sur un site marchand : proposition d'un modèle conceptuel de recherche [Exploratory study on the effects of mental imagery stemming from the presentation of products on a retail website: Proposal of an abstract model]. Management \& Avenir, 4, 101-123.

Lorant, J., \& Nicolas, N. (2004). Validation de la traduction française du Movement Imagery Questionnaire - Revised (MIQ-R) [Validation of the French translation of the 
Movement Imagery Questionnaire-Revised (MIQ-R)]. Sciences et Motricité, 53, 5768. doi:10.3917/sm.053.0057

Martin, K. A., \& Hall, C. R. (1995). Using mental imagery to enhance intrinsic motivation. Journal of Sport \& Exercise Psychology, 17, 54-69.

McPhee, J. S., French, D. P., Jackson, D., Nazroo, J., Pendleton, N., \& Degens, H. (2016). Physical activity in older age: Perspectives for healthy ageing and frailty. Biogerontology, 17(3), 567-580. doi:10.1007/s10522-016-9641-0

Missbach, B., Florack, A., \& Konig, J. (2015). Mental imagery and food consumption. Frontiers in Psychiatry, 6, 48. doi:10.3389/fpsyt.2015.00048

Morton, K., Sutton, S., Hardeman, W., Troughton, J., Yates, T., Griffin, S., . . Eborall, H. (2015). A Text-Messaging and Pedometer Program to Promote Physical Activity in People at High Risk of Type 2 Diabetes: The Development of the PROPELS FollowOn Support Program. JMIR Mhealth and Uhealth, 3(4), e105. doi:10.2196/mhealth.5026

Muller, A. M., Khoo, S., \& Morris, T. (2016). Text Messaging for Exercise Promotion in Older Adults From an Upper-Middle-Income Country: Randomized Controlled Trial. Journal of Medical Internet Research, 18(1), e5. doi:10.2196/jmir.5235

Murphy, S. M., \& Jowdy, D. P. (1992). Imagery and mental practice. In T. S. Horn (Eds.), Advances in sport psychology (pp. 221-250). Champaign, IL: Human Kinetics.

Myers, M., \& Gonda, G. (1986). Research on Physical Activity in the Elderly: Practical Implications for Program Planning. Canadian Journal on Aging, 5, 175-188. doi:https://doi.org/10.1017/S0714980800005092

Nguyen, H. Q., Gill, D. P., Wolpin, S., Steele, B. G., \& Benditt, J. O. (2009). Pilot study of a cell phone-based exercise persistence intervention post-rehabilitation for COPD. International Journal of Chronic Obstructive Pulmonary Disease, 4, 301-313. 
1 Nordin, S. M., \& Cumming, J. (2007). Where, when and how: A quantitative account of dance imagery. Research Quarterly for Exercise and Sport, 78, 390-395.doi:10. $1080 / 02701367.2007 .10599437$

4

O'Reilly, G. A., \& Spruijt-Metz, D. (2013). Current mHealth technologies for physical activity assessment and promotion. American Journal of Preventive Medicine, 45(4), 501-507. doi:10.1016/j.amepre.2013.05.012

Paivio, A. (1985). Cognitive and motivational functions of imagery in human performance. Canadian Journal of Applied Sport Sciences, 10, 22-28. Retrieved from http:// www.ncbi.nlm.nih.gov/pubmed/4085129.

Prestwich, A. Perugini, M., \& Hurling, R. (2010). Can implementation intentions and text messages promote brisk walking? A randomized trial. Health Psychology, 29, 40-49.

Reiser, M., Busch, D., \& Munzert, J. (2011). Strength gains by motor imagery with different ratios of physical to mental practice. Frontiers in Psychology, 2, 194. doi:10.3389/fpsyg.2011.00194

Robin, N., Dominique, L., Toussaint, L., Blandin, Y., Guillot, A., \& Le Her, M. (2007). Effects of motor imagery training on returning serve accuracy in tennis: The role of imagery ability. International Journal of Sport \& Exercise Psychology, 2, 177-188. doi:10.1080/1612197X.2007.9671818

Rushall, B. S. (1991). Imagery training in sports: A handbook for athletes, coaches, and sport psychologists. Spring Valley, CA: Sports Science Associates. Published in Australia by the Australian Coaching Council, Canberra, ACT.

Salmon, J., Crawford, D., Owen, N., Bauman, A., \& Sallis, J. F. (2003). Physical activity and sedentary behavior: A population-based study of barriers, enjoyment, and preference. Health Psychology, 22, 178-188. 
1 Seiler, B., Monsma, E., \& Newman-Norlund, R. (2015). Biological Evidence of Imagery Abilities: Intraindividual Differences. Journal of Sport and Exercise Psychology, 37, 421-35. doi:10.1123/jsep.2014-0303

Short, S. E., Tenute, A., \& Feltz, D. L. (2005). Imagery use in sport: Mediational effects for efficacy. Journal of Sports Sciences, 23, 951-960.

Slimani, M., Tod, D., Chaabene, H., Miarka, B., \& Chamari, K. (2016). Effects of Mental Imagery on Muscular Strength in Healthy and Patient Participants: A Systematic Review. Journal of Sports Science and Medicine, 15(3), 434-450.

Stacey, C., Kozma, A., \& Stones, M. J. (1985). Simple Cognitive and Behavioural Changes Resulting from Improved Physical Fitness in Persons over 50 Years of Age. Canadian Journal on Aging, 4, 67-74. doi:https://doi.org/10.1017/S0714980800015889

Studenski, S., Perera, S., Hile, E., Keller, V., Spadola-Bogard, J., \& Garcia, J. (2010). Interactive video dance games for healthy older adults. Journal of Nutrition Health and Aging, 14(10), 850-852.

Sun, F., Norman, I. J., \& While, A. E. (2013). Physical activity in older people: a systematic review. BMC Public Health, 13, 449. doi:10.1186/1471-2458-13-449

Tabak, M., Op den Akker, H., \& Hermens, H. (2014). Motivational cues as real-time feedback for changing daily activity behavior of patients with COPD. Patient Education and Counseling, 94, 372-378.

Target, C. (2012). La method Target [The target method]. Editions Chiron.

Taylor, D. (2014). Physical activity is medicine for older adults. Postgraduate Medical Journal, 90(1059), 26-32. doi:10.1136/postgradmedj-2012-131366

Vandelanotte, C., Short, C., Plotnikoff, R. C., Hooker, C., Canoy, D., Rebar, A., . . Duncan, M. J. (2015). TaylorActive--Examining the effectiveness of web-based personally- 
tailored videos to increase physical activity: A randomised controlled trial protocol. BMC Public Health, 15, 1020. doi:10.1186/s12889-015-2363-4

Verardi, D., Dahourou, J., Ah-Kion, U., Bhowon, C.N., Tseung, D., Amoussou-Yeye, M., ... Rossier, J. (2010). Psychometric Properties of the Marlowe-Crowne Social Desirability Scale in Eight African Countries and Switzerland. Journal of CrossCultural Psychology, 41, (1), 19-34.

\footnotetext{
${ }^{\mathrm{i}}$ World Health Organization Diet and Physical Activity Factsheet. Secondary Diet and Physical Activity Factsheet 2013. http://www.who.int/dietphysicalactivity/factsheet inactivity/en/index.html

${ }^{i i}$ World Health Organization. Global status report on noncommunicable diseases 2010. Geneva: WHO Press.

iii Tech Tracker Quarterly Release: Q4 2013. Ipsos Media; 2013. [2015-08-03]. webcite https://www.ipsosmori.com/DownloadPublication/1630_IpsosMediaCT_Techtracker_Q4_2013.pdf.

${ }^{\text {iv }}$ A nation addicted to smartphones. London, UK: Ofcom; 2011. [2015-08-03]. webcite http://media.ofcom.org.uk/news/2011/a-nation-addicted-to-smartphones/

${ }^{\vee}$ Selwyn N., Gorard S., Furlong J., Madden L. (2003). Older adults' use of information and communications technology in everyday life. Ageing and Society, 23, 561-582
}

Table 1

Participants demographic and clinical characteristics

\begin{tabular}{cccc}
\hline Variables & Imagery 1 Group & Imagery 2 Group & Placebo Group \\
& $(n=30)$ & $(n=28)$ & $(n=29)$ \\
\hline
\end{tabular}

\section{Demographics}

Sex

Age (years)

Marital Status

Race/ethnicity

Education

Medium financial income

\section{History of disease}

Bone

Cancer

Cardiovascular

Thyroid

Spine

Other

No disease reported

\section{$57 \%$ females}

$54 \%$ females

$52 \%$ females

$61.59(7.35)$

$62.54(6.54)$

$64.48(5.23)$

47\% Married

43\% Married

$52 \%$ Married

$100 \%$ White

97\% White

100\% White

$50 \%$ College

$46 \%$ College

$52 \%$ College

$97 \%$

$100 \%$

$100 \%$

$\begin{array}{ccc}13 \% & 7 \% & 3 \% \\ 10 \% & 14 \% & 17 \% \\ 13 \% & 10 \% & 3 \% \\ 7 \% & 11 \% & 3 \% \\ 3 \% & 0 \% & 7 \% \\ 17 \% & 14 \% & 21 \% \\ 40 \% & 46 \% & 38 \%\end{array}$


Table 2

Descriptive statistics for imagery use and imagery ability.

\begin{tabular}{lccc}
\hline Measure & $M$ & $S D$ & Range \\
\hline SIQ & 1.62 & 0.57 & \\
Cognitive Specific & 1.28 & 0.50 & $1-3$ \\
Cognitive General & 3.93 & 0.74 & $2-3$ \\
Motivational Specific & 1.85 & 0.63 & $1-4$ \\
Motivational General-Arousal & 1.75 & 0.64 & $1-3$ \\
Motivational General-Mastery & & & $19-28$ \\
MIQ-R & 23.83 & 1.87 & $18-28$ \\
Visual & 21.35 & 1.84 & \\
Kinaesthetic & & & \\
\hline
\end{tabular}

Table 3

Mean scores and increase of Aerobic Physical Activity (APA) of the groups (Low scorers, Average scorers, and High scorers) according to the French version of the Marlowe-Crowne measure of Social Desirability scale (MCSD).

Groups $\quad M 1$ MCSD scores $\quad S D$ Range $M 2$ increase of APA $S D$

\begin{tabular}{lccccc}
\hline $\begin{array}{l}\text { Low scorers } \\
(\mathrm{n}=13)\end{array}$ & 2,46 & 0,49 & $1-3$ & 23,38 & 14,89 \\
$\begin{array}{l}\text { Average scorers } \\
(\mathrm{n}=57)\end{array}$ & 5,5 & 0,93 & $4-7$ & 26,95 & 18,74 \\
$\begin{array}{l}\text { High scorers } \\
(\mathrm{n}=17)\end{array}$ & 9,17 & 1,07 & $8-11$ & 21,97 & 15,46 \\
\hline
\end{tabular}

Note: M1 = Mean MCSD scores, M2 = Mean increase of minutes of Aerobic Physical Activity (mean differences between morning text and no morning text conditions minutes of APA). 
Table 4

Mean Marlowe-Crowne measure of Social Desirability (MCSD) scale scores of the groups (Imagery 1, Imagery 2, and Placebo).

\begin{tabular}{lcc}
\hline Groups & $M(S D)$ & Range \\
\hline $\begin{array}{l}\text { Imagery 1 } \\
(\mathrm{n}=30)\end{array}$ & $5.63(2.25)$ & $2-11$ \\
$\begin{array}{l}\text { Imagery } 2 \\
(\mathrm{n}=28)\end{array}$ & $5.82(2.35)$ & $2-10$ \\
$\begin{array}{l}\text { Placebo } \\
(\mathrm{n}=29)\end{array}$ & $5.69(2.32)$ & $1-11$ \\
\hline
\end{tabular}

Table 5

Weekly minutes of aerobic physical activity, by conditions, for the Imagery and Placebo Groups

\begin{tabular}{|c|c|c|c|c|c|c|c|c|}
\hline \multirow{2}{*}{$\begin{array}{c}\text { Groups } \\
\text { Conditions }\end{array}$} & \multicolumn{2}{|c|}{ Week 1} & \multicolumn{2}{|c|}{ Week 2} & \multicolumn{2}{|c|}{ Week 3} & \multicolumn{2}{|c|}{ Week 4} \\
\hline & $M$ & $(S D)$ & $M$ & $(S D)$ & $M$ & $(S D)$ & $M$ & $(S D)$ \\
\hline \multicolumn{9}{|l|}{ Imagery $1(n=30)$} \\
\hline Imagery morning text & 98.44 & $(29.31)$ & 99.82 & $(28.01)$ & $\operatorname{xxxx}$ & $\operatorname{xxxx}$ & $\mathrm{XXXX}$ & $\mathrm{xxxx}$ \\
\hline No morning text & $\operatorname{xxxx}$ & $\operatorname{xxxx}$ & $\mathrm{xxxx}$ & $\mathrm{XXXX}$ & 72.55 & $(33.17)$ & 73.03 & $(29.84)$ \\
\hline \multicolumn{9}{|l|}{ Imagery $2(n=28)$} \\
\hline Imagery morning text & $\operatorname{xxxx}$ & $\operatorname{xxxx}$ & $\mathrm{xxxx}$ & $\mathrm{XXXX}$ & 97.96 & $(26.60)$ & 101.51 & $(26.73)$ \\
\hline No morning text & 73.27 & $(32.30)$ & 72.03 & $(35.75)$ & $\mathrm{xxxx}$ & $\mathrm{xxxx}$ & $\mathrm{xxXX}$ & $\mathrm{xxxx}$ \\
\hline \multicolumn{9}{|l|}{ Placebo $(n=29)$} \\
\hline Placebo morning text & 72.75 & $(29.20)$ & 71.44 & $(32.80)$ & $\mathrm{xxxx}$ & $\mathrm{xxxx}$ & $\mathrm{xxxx}$ & $\mathrm{xxxx}$ \\
\hline No morning text & $\mathrm{xxxx}$ & $\mathrm{xxxx}$ & $\mathrm{XXXX}$ & $\mathrm{XXXX}$ & 72.03 & $(26.97)$ & 70.79 & $(30.50)$ \\
\hline
\end{tabular}

Note: $\mathrm{M}=$ Mean weekly minutes of aerobic physical activity, $(\mathrm{SD})=$ standard deviation

Note: $\mathrm{M}=$ Mean MCSD scores, $(\mathrm{SD})=$ standard deviation 


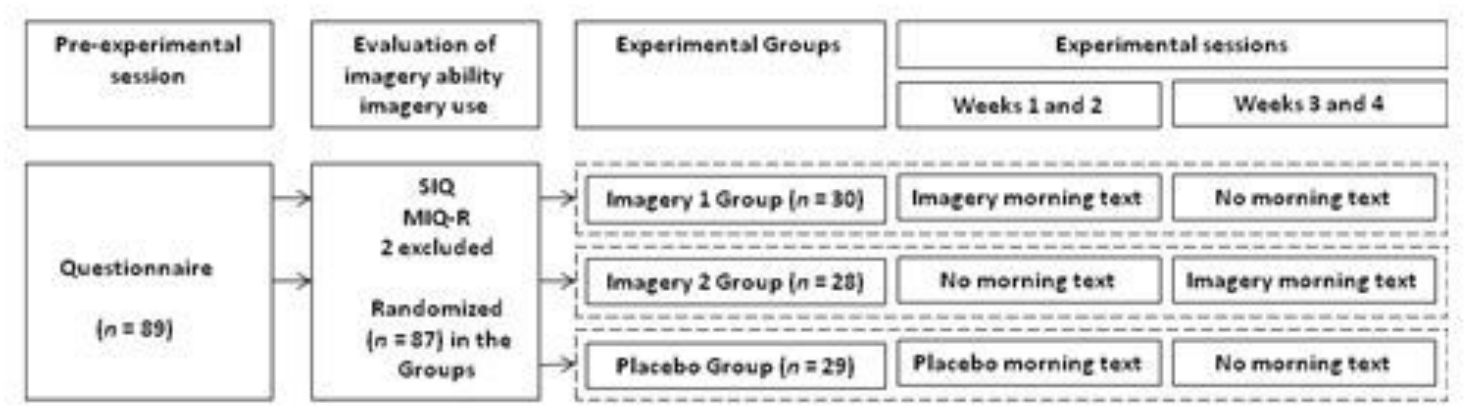

Figure 1. Time course of the experimental design

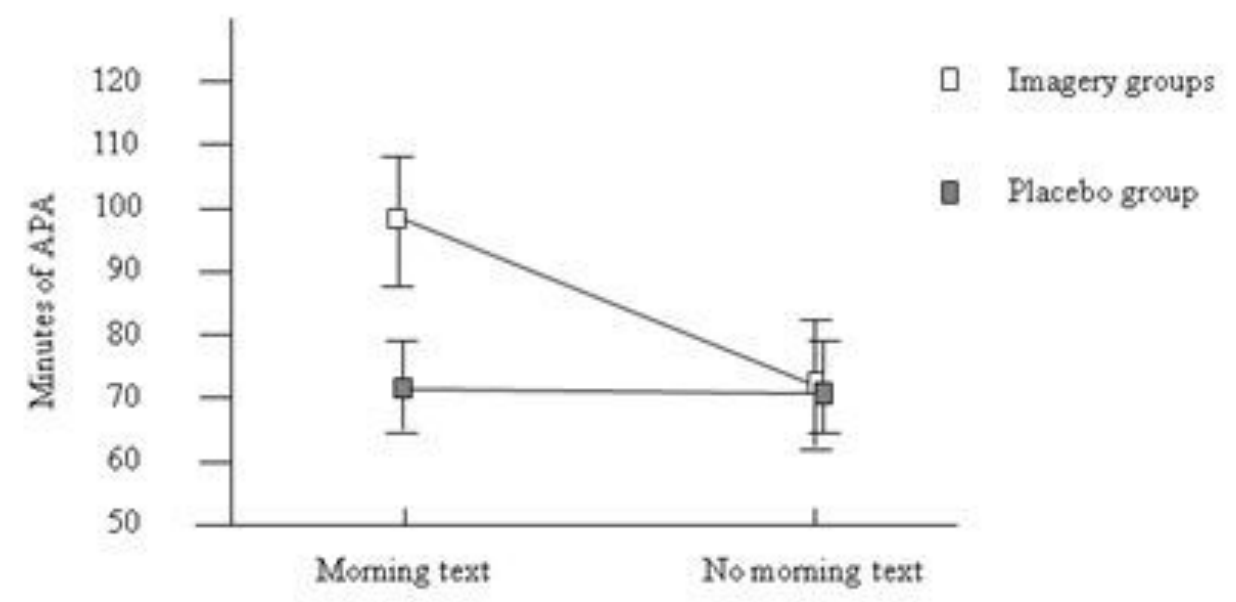

Figure 2. Significant interaction between condition(Moming text vs. No moming text) and groups (Imagery vs. Placebo) by ANOVA. I-beams indicates the $95 \%$ confidence intervals for the mean values. 


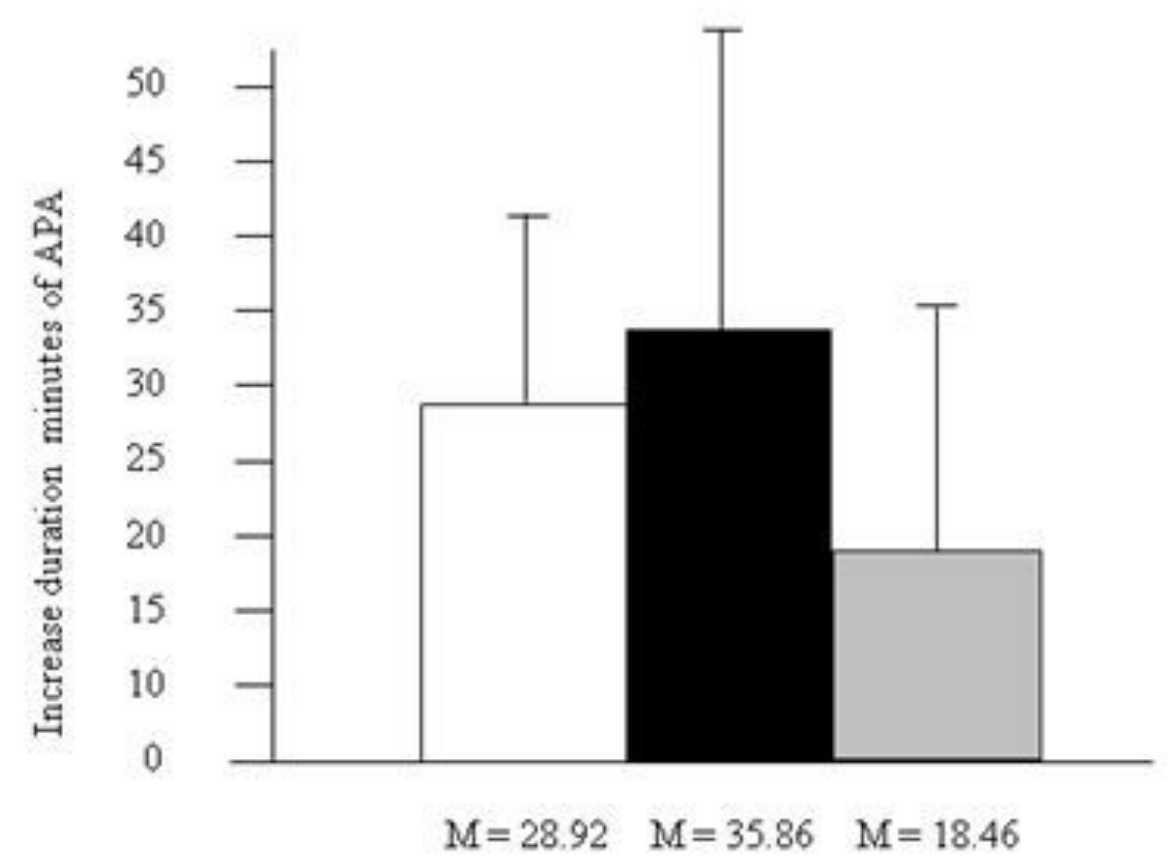

Figure 3. Main effect of the High (white bars), Medium (black bars) and Low (grey bars) SIQ-MS groups on the increase of the duration of a erobic physical activity (APA). I-beams indicates the $95 \%$ confidence intervals for the mean values. 